Thorax (1948), 3, 166.

\title{
EXTRAPLEURAL PNEUMOTHORAX: A REVIEW OF 128 CASES \\ BY
}

\author{
A. T. M. ROBERTS \\ From the Brompton Hospital, London
}

The first extrapleural pneumothorax induced at the Brompton Hospital, London, was performed by Mr. J. E. H. Roberts, on May 10, 1937, and this was the first operation of its kind to be performed in England or America since the introduction of the modern operation by Graf. During the following five years, up to May, 1942, the operation was attempted on 147 occasions at the Brompton Hospital. This paper is an analysis of these cases, based on a study of the pre-operative history in each case, and as complete a follow-up as possible.

\section{Analysis of Cases Reviewed}

OPerative Procedures.-The operative procedures are summarized in Table I. On 16 (11 per cent) of the 147 occasions the operation was aban-

TABLE I

OPERATIVE PROCEDURES IN 147 CASES IN WHICH EXTRAPLEURAL PNEUMOTHORAX WAS ATTEMPTED BETWEEN MAY, 1937, AND MAY, 1942

\begin{tabular}{|c|c|c|}
\hline \multicolumn{2}{|l|}{ Procedure } & Number \\
\hline $\begin{array}{l}\text { Abandoned on table } \\
\text { Thoracoplasty performed } \\
\text { Case notes missing } \\
\text { "Standard" operation } \quad . . \\
\text { "Combined" operation } \quad . .\end{array}$ & $\begin{array}{ll}\cdots & \cdots \\
\cdots & \cdots \\
\cdots & \cdots \\
\cdots & \cdots\end{array}$ & $\begin{array}{r}12 \\
4 \\
3 \\
100 \\
28\end{array}$ \\
\hline Total operations attemp & . & 147 \\
\hline
\end{tabular}

doned on the operating table due to the density of adhesions in the extrapleural plane; in four of these cases the surgeon proceeded to perform a formal thoracoplasty, while in the remaining twelve the patient was returned to the ward after closure of the wound. A further three cases have had to be omitted from this review because the case notes were missing. The remaining 128 patients have been traced as far as possible.
The cases fall into two main groups which have been studied separately:

1. One hundred cases in which a straightforward extrapleural strip and apicolysis was performed-the "standard" operation.

2. Twenty-eight cases in which the extrapleural and intrapleural spaces were joined, either at or shortly after operation, and refills continued to the combined intra-extrapleural space - the "combined" operation.

In five cases an extrapleural pneumothorax was induced on each side at separate operations, but in only two cases were both operations performed at the Brompton Hospital.

Age Distribution.-The youngest patient was a girl of 13 years, while the eldest was a man of 58 years. In 12 cases the patient was under 20 years old. The ages of the patients, male and female, at the time of operation are shown in Table II.

TABLE II

AGE AND SEX DISTRIBUTION

\begin{tabular}{|c|c|c|c|c|c|c|}
\hline Age in years & $10-19$ & $20-29$ & $30-39$ & $40-49$ & $50-59$ & Total \\
\hline $\begin{array}{l}\text { Male } \\
\text { Female : }\end{array}$ & $\begin{array}{l}3 \\
9\end{array}$ & $\begin{array}{l}19 \\
38\end{array}$ & $\begin{array}{l}26 \\
18\end{array}$ & $\begin{array}{r}10 \\
4\end{array}$ & 1 & $\begin{array}{l}59 \\
69\end{array}$ \\
\hline
\end{tabular}

LENGTH OF FolLOW-UP.-Some of the patients are still under the care of the Brompton Hospital, but in the majority the follow-up has only been possible with the help of tuberculosis officers, superintendents of sanatoria, and general practitioners throughout the country. Details of the length of follow-up, together with the numbers known to be living or dead, are summarized in Table III.

Of the 128 patients, 118 have been traced either to death or to within a year of the date of followup, while the remaining ten have been traced for 
varying periods up to eight years from the date of the operation. In only five (4 per cent) was the follow-up less than five years. Of the 128 operations, 108 were performed during 1937 and 1938, so that an eight- to nine-year follow-up has been possible in most cases. Fifty-six patients are known to be dead. The overall average followup of the remaining seventy-two patients, known to be living at the time up to which they were traced, is 8.0 years.

TABLE III

LENGTH OF FOLLOW-UP IN YEARS

\begin{tabular}{|c|c|c|c|c|c|c|c|c|c|c|c|}
\hline \multirow{2}{*}{$\begin{array}{l}\text { Year of } \\
\text { operation }\end{array}$} & \multirow{2}{*}{$\begin{array}{l}\text { Total } \\
\text { cases }\end{array}$} & \multirow{2}{*}{ Dead } & \multicolumn{9}{|c|}{ Length of follow-up, in years } \\
\hline & & & 9 & 8 & 7 & 6 & 5 & 4 & 3 & 2 & 1 \\
\hline $\begin{array}{l}1937 \\
1938 \\
1939 \\
1940 \\
1941 \\
1942\end{array}$ & $\begin{array}{r}46 \\
62 \\
9 \\
6 \\
4 \\
1\end{array}$ & $\begin{array}{r}24 \\
25 \\
6 \\
-1 \\
\end{array}$ & $\begin{array}{l}20 \\
11 \\
= \\
-\end{array}$ & $\begin{array}{l}21 \\
\text { - } \\
\text { - } \\
-\end{array}$ & $\begin{array}{l}-1 \\
3 \\
1 \\
-\end{array}$ & $\begin{array}{l}- \\
\frac{3}{3} \\
-\end{array}$ & $\begin{array}{c}\overline{2} \\
\overline{3} \\
1\end{array}$ & $\begin{array}{l}\bar{Z} \\
\frac{1}{-}\end{array}$ & $\begin{array}{l}= \\
\bar{Z} \\
=\end{array}$ & $\begin{array}{l}1 \\
1 \\
= \\
-\end{array}$ & $\begin{array}{l}\overline{1} \\
\overline{1} \\
-\end{array}$ \\
\hline Totals & 128 & 56 & 31 & 22 & 5 & 3 & 6 & 1 & - & 2 & 2 \\
\hline
\end{tabular}

TABLE IV

INTERVAL BETWEEN OPERATION AND DEATH IN THE FORTY-FIVE PATIENTS OUT OF THE ONE HUNDRED SUBMITTED TO THE "STANDARD" OPERATION WHO WERE DEAD AT THE TIME OF FOLLOW-UP

\begin{tabular}{c|c|c|c|c|c|c|c|c|c|c}
\hline \multicolumn{3}{c|}{ Months } & \multicolumn{8}{c}{ Years } \\
\hline Under 3 & 3 & 6 & 1 & 2 & 3 & 4 & 5 & 6 & 7 \\
\hline 8 & 4 & 4 & 10 & 4 & 5 & 3 & 2 & 3 & - & 2 \\
\hline
\end{tabular}

TABLE V

CAUSES OF FOURTEEN POSTOPERATIVE DEATHS AFTER THE "STANDARD" OPERATION

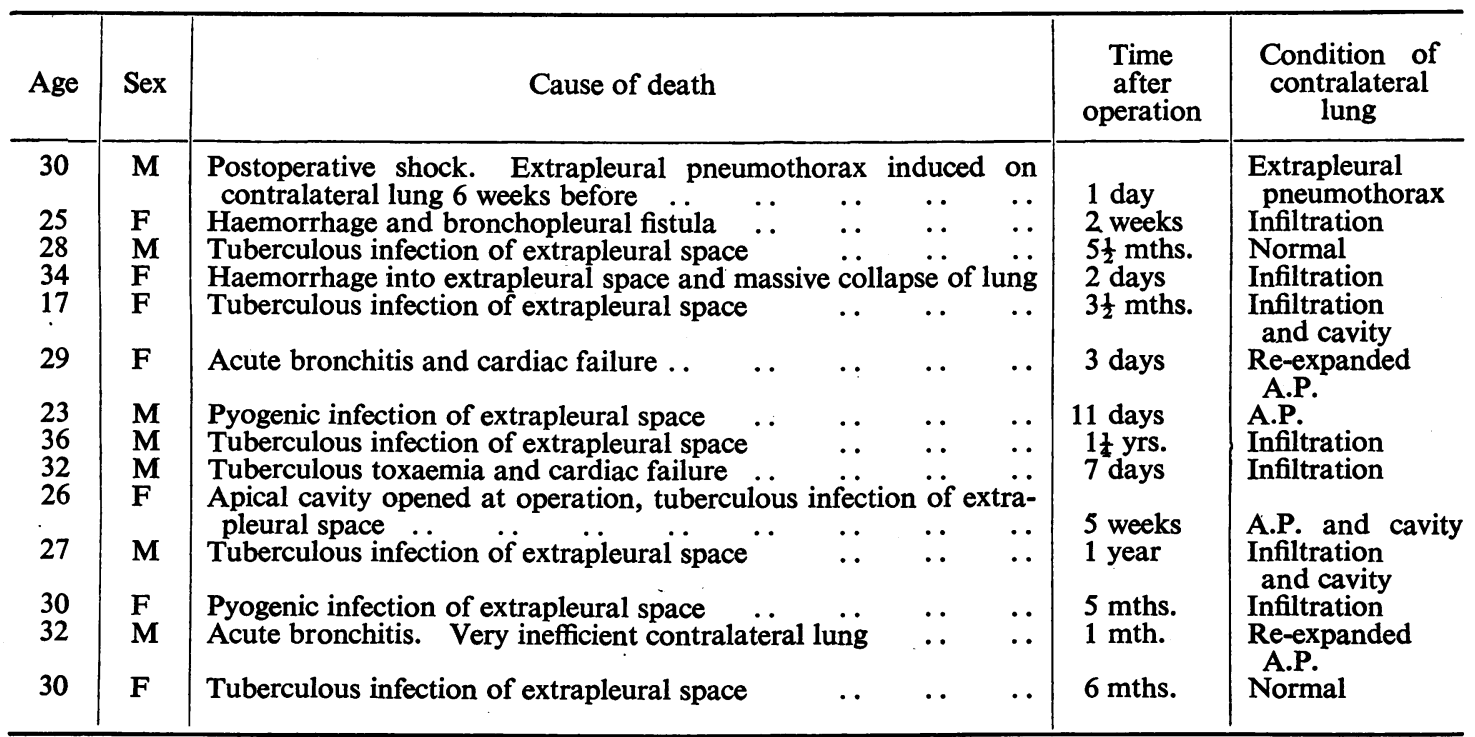


TABLE VI

CAUSES OF FOURTEEN LATE DEATHS AFTER THE "STANDARD" OPERATION

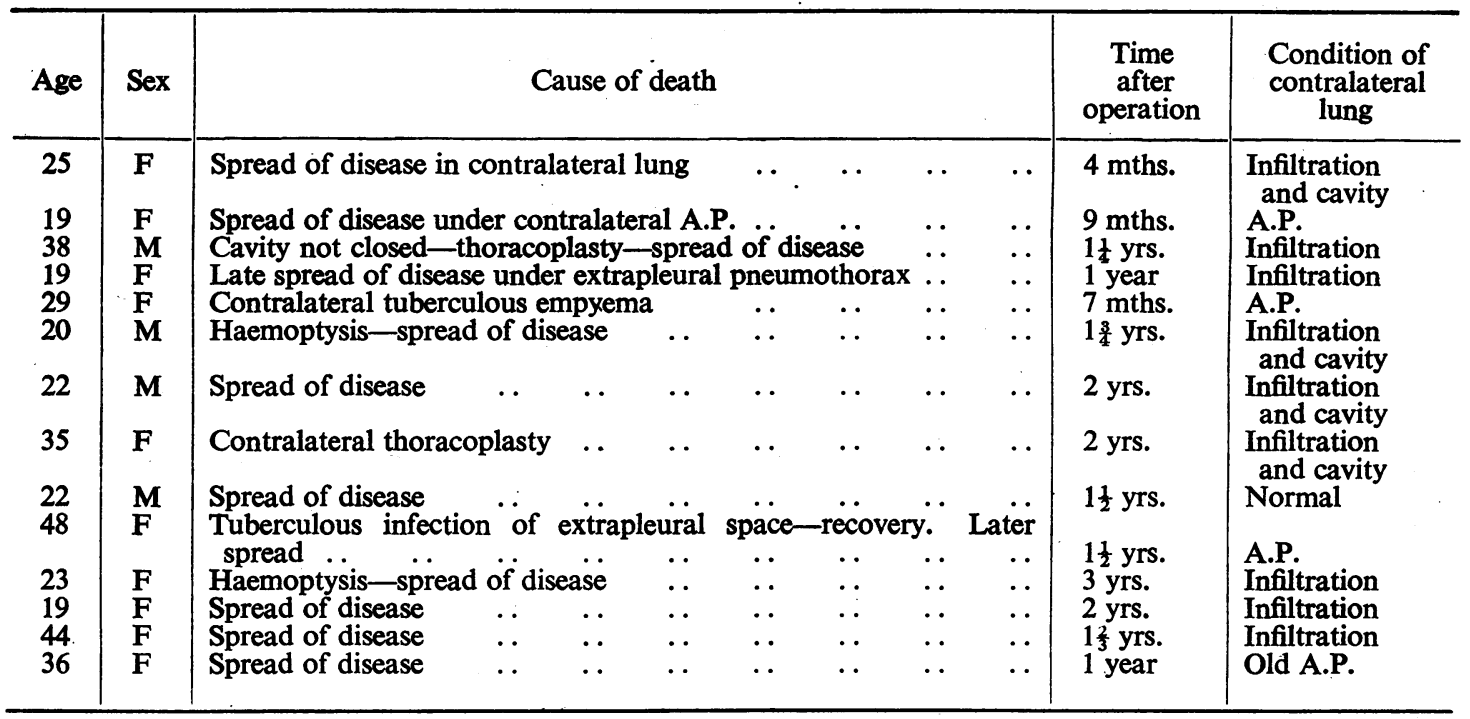

Results in One. Hundred Patients Submitted TO THE "STANDARD" OpERATION

In sixty-six of a hundred cases submitted to the "standard" operation the disease was bilateral at the time of operation. In seventy-eight an artificial pneumothorax on the operated side had been attempted and failed or had been abandoned because of contraselectivity.

Deaths.-Forty-five of the patients are known to be dead. The deaths, which occurred at varying intervals after operation as shown in Table IV, and which in many cases could not be attributed to the operation, have been divided into three categories -postoperative, late, and remote.

Postoperative deaths (Table V).-Fourteen deaths can be attributed to the effects of the operation or its immediate complications.

Late deaths (Table VI).-Fourteen deaths were due to spread of the disease in spite of the operation, although the operation itself was not a factor.

Remote deaths.-Fifteen patients enjoyed a period of normal health after apparent control of their disease by the operation, only to relapse later and succumb to spread of the disease. Two further deaths were from non-tuberculous causesgastric ulcer in one case and nephritis in the other -but in neither was the tuberculous disease completely under control at the time of death.

Living Patients.-Fifty-five of the hundred patients in the "standard" series were alive after an average period of eight years. Forty-six were free of symptoms and were doing full-time work with their disease quiescent or arrested. Refills were still being given to three, a thoracoplasty had been performed in seven, and an oleothorax in two. In the remaining thirty-four cases the extrapleural pneumothorax had obliterated or had been voluntarily abandoned.

Nine patients still had symptoms of active disease. Two of these were still having refills, one had had an oleothorax, and six had discharging sinuses-five following thoracoplasty and one following drainage of a late pyogenic infection of

TABLE VII

PROGRESS OF ONE HUNDRED PATIENTS SUBMITTED TO THE "STANDARD" OPERATION

\begin{tabular}{|c|c|c|c|c|c|}
\hline Deaths & $\begin{array}{l}\text { Postoperative } \\
\text { Late .. } \\
\text { Remote .. }\end{array}$ & $\begin{array}{l}. . \\
. .\end{array}$ & $\begin{array}{l}. \\
\therefore \\
. .\end{array}$ & $\begin{array}{l}14 \\
14 \\
17\end{array}$ & $45 \%$ \\
\hline $\begin{array}{cc}\text { Alive } & \text { and } \\
\text { well } & \ldots\end{array}$ & $\begin{array}{l}\text { Continuing refi } \\
\text { Voluntarily aba } \\
\text { Obliterated } \\
\text { Thoracoplasty } \\
\text { Oleothorax }\end{array}$ & $\begin{array}{l}\text { lls } \\
\text { indonec } \\
. . \\
\ldots \\
. .\end{array}$ & $\begin{array}{l}. . \\
\because .\end{array}$ & $\begin{array}{r}3 \\
24 \\
10 \\
7 \\
2\end{array}$ & $46 \%$ \\
\hline $\begin{array}{c}\text { Alive with } \\
\text { symptoms }\end{array}$ & $\begin{array}{l}\text { Continuing refi } \\
\text { Voluntarily aba } \\
\text { Obliterated } \\
\text { Thoracoplasty } \\
\text { Oleothorax }\end{array}$ & $\begin{array}{l}\text { lls } \\
\text { indone } \\
. . \\
\ldots \\
\ldots\end{array}$ & $\begin{array}{l}. . \\
\cdots\end{array}$ & $\begin{array}{l}2 \\
1 \\
5 \\
1\end{array}$ & $9 \%$ \\
\hline
\end{tabular}


the extrapleural space. The progress of the hundred patients submitted to the "standard" procedure is summarized in Table VII.

Postoperative Complications of the "StandARD" OPERATION.-Tuberculous Empyema of the Extrapleural Space.-This occurred in thirteen patients, of whom ten subsequently died (six postoperative, one late, and three remote deaths). Two patients were alive and well after thoracoplasty and one was alive and well after the infection had subsided spontaneously. Cases in which only an occasional tubercle bacillus was found in the extrapleural fluid are not included in this group.

Pyogenic Infection of the Extrapleural Space. -Infection with streptococci, staphylococci, or pneumococci developed in fourteen patients. Intercostal drainage or rib resection was performed on eleven of these patients. Four were dead (two postoperative and two remote deaths), four were alive and well, and six were alive with discharging sinuses. Of the nine patients subsequently submitted to thoracoplasty, only one has since died.

Bronchopleural Fistula.-Bronchopleural fistula complicated infection of the extrapleural space in seven cases. Three of these patients subsequently died. Of the other four, two recovered spontaneously after abandonment of refills, one was alive and well after thoracoplasty, and one had a dicharging sinus after thoracoplasty.

Haemorrhage.-Some oozing of blood into the extrapleural space after operation is inevitable. In eight cases, however, serious haemorrhage occurred, and in two it was the cause of postoperative death. The remaining six patients recovered eventually after thoracoscopy with removal of the blood and blood clot and adequate transfusions.

Atelectasis.-The degree of relaxation of the lung after the operation varied considerably and in twelve cases amounted to a complete and persistent atelectasis of the whole lung. Six of these patients eventually died, four from tuberculous empyema, one from added haemorrhage, and one from the resultant anoxia. In the remaining six cases re-expansion slowly took place over a period of months and the patients were alive and well at the time of follow-up.

Effusion.-In most cases a sterile effusion. developed after operation, but in the majority it eventually absorbed leaving a dry space. In fourteen the effusion persisted, slowly turned to sterile pus and necessitated the abandonment of the pneumothorax.

The total of sixty-eight complications listed above actually occurred in forty-nine patients, since some patients suffered more than one complication. Thus approximately 50 per cent of patients developed some postoperative complication.

\section{Results in Twenty-Eight Patients Submitted TO THE " COMBINED" OPERATION}

Nineteen of the twenty-eight "combined" operations were performed in the presence of a contraselective artificial pneumothorax, the septum between intrapleural and extrapleural spaces being divided widely at operation. In the remaining nine cases an artificial pneumothorax was induced at operation, deliberately in six instances but accidentally in three. The septum was divided at operation in five of these cases but in the other four it was divided by cautery through a thorascope several weeks later.

Deaths.-Eleven patients are known to be dead (six postoperative and five remote deaths), giving an overall mortality of 39 per cent and a postoperative mortality of 21 per cent. Five of the postoperative deaths were due to tuberculous infection of the combined intra-extrapleural space, while the sixth followed a first-stage thoracoplasty performed to deal with a bronchopleural fistula.

Living Patients.-Twelve patients, of whom five were still having refills, were alive and well. Five patients, of whom two were still having refills, were alive with symptoms. The progress of the twenty-eight patients submitted to the "combined" operation is summarized in Table VIII.

\section{TABLE VIII}

PROGRESS OF TWENTY-EIGHT PATIENTS SUBMITTED TO THE "COMBINED" OPERATION

\begin{tabular}{|c|c|c|c|c|c|}
\hline Deaths & $\begin{array}{l}\text { Postope } \\
\text { Late .. } \\
\text { Remote }\end{array}$ & $\begin{array}{l}\text { ve } \\
\ldots \\
\cdots\end{array}$ & $\begin{array}{l}\ddot{ } \\
\ddot{*}\end{array}$ & $\begin{array}{l}6(21 \%) \\
5(18 \%)\end{array}$ & $39 \%$ \\
\hline $\begin{array}{r}\text { Alive and } \\
\text { well }\end{array}$ & $\begin{array}{l}\text { Continu } \\
\text { Volunta } \\
\text { Oblitera } \\
\text { Thoraco }\end{array}$ & $\begin{array}{c}\text { refi } \\
\text { aba } \\
\text { sty }\end{array}$ & $\begin{array}{c}\ldots \\
\cdots \\
\cdots\end{array}$ & $\begin{array}{l}5 \\
3 \\
2 \\
2\end{array}$ & $43 \%$ \\
\hline $\begin{array}{c}\text { Alive with } \\
\text { symptoms }\end{array}$ & $\begin{array}{l}\text { Continu } \\
\text { Volunta } \\
\text { Oblitera } \\
\text { Thoraco }\end{array}$ & $\begin{array}{c}\text { refi } \\
\text { aba } \\
\text { sty }\end{array}$ & $\begin{array}{c}\ldots \\
\cdots \\
\cdots\end{array}$ & $\frac{2}{1}$ & $18 \%$ \\
\hline
\end{tabular}

Postoperative Complications of the " COMBINED " OPERATION.-Tuberculous infection of the extrapleural space occurred in eight patients, representing 28 per cent of the total and, as mentioned above, was the cause of postoperative death in five cases. Pyogenic infection of the extrapleural space 
and bronchopleural fistula occurred in one case each, and persistent effusion in four cases. As would be expected, atelectasis of the whole lung was not infrequent-it occurred in ten patients, five of whom developed tuberculous infection of the combined space, which led to the patient's death. No case of severe haemorrhage was seen in the "combined" series.

These twenty-four complications occurred in sixteen patients, so that 66 per cent of patients developed one or more complications.

\section{THORACOPLASTY AFTER EXTRAPLEURAL PNEUMOTHORAX}

In the whole series of 128 cases, thoracoplasty was eventually performed in twenty-four (19 per cent) for the following reasons:

1. Tuberculous infection of the extrapleural space-five cases. One patient died after operation, three were alive and well, and one was alive with a sinus.

2. Pyogenic infection of the extrapleural space-ten cases. One remote death, five alive and well, and four alive with sinuses.

3. Bronchopleural fistula-one patient who died after the first stage of the thoracoplasty.

4. Disease not controlled by extrapleural pneumothorax - seven cases. One postoperative, one late, and three remote deaths. One alive and well and one alive with a sinus.

5. Closure of the extrapleural space-one patient, seven and a half years after the original operation, now alive and well.

The progress of the twenty-four patients on whom thoracoplasty was eventually performed is summarized in Table IX.

TABLE IX

RESULTS IN TWENTY-FOUR PATIENTS SUBMITTED TO THORACOPLASTY AFTER EXTRAPLEURAL PNEUMOTHORAX

\begin{tabular}{|c|c|c|c|c|c|}
\hline Deaths & No. & $\%$ & Alive & No. & $\%$ \\
\hline $\begin{array}{l}\text { Postoperative } \\
\text { Late } \quad \text {.. } \\
\text { Remote }\end{array}$ & $\begin{array}{l}3 \\
1 \\
4\end{array}$ & 33 & $\begin{array}{c}\text { Well } \\
\text { With } \\
\text { symptoms }\end{array}$ & $\begin{array}{r}10 \\
6\end{array}$ & 42 \\
\hline
\end{tabular}

\section{The Fate of the Extrapleural Space after}

\section{VOLUNTARY ABandonMENT OF REFILLS}

Thirty-one ( 24 per cent) of the 128 patients are known to have had their refills abandoned voluntarily after an average period of five years; an average follow-up of a further three and a half years after abandonment has been possible.
Three and three and a half years respectively after abandonment of refills two patients died from spread of disease in the contralateral lung; in both cases the lesion for which the extrapleural pneumothorax had been performed was controlled at the time of death. In two cases thoracoplasty was performed on the extrapleural pneumothorax side, one immediately after abandonment of a very large extrapleural space and the other three and a half years later. In both cases the thoracoplasty was necessitated by reactivation of the original lesion, but both patients were alive and well at the time of follow-up.

The remaining twenty-seven patients (twentyfour "standard" and three "combined") had remained well and working for an average period of three and a half years. No relapse of the tuberculous process or any other complication had occurred after the last refill in these cases. In thirteen of the twenty-seven cases the extrapleural space was filled by a "cap" of sterile fluid and in five by an area of fibrosis. In the remaining nine details were not available.

\section{Factors Affecting Prognosis}

The incidence of postoperative deaths and of complications is high in this series as a whole, and it is not surprising that the procedure fell into relative disuse-as is strikingly borne out by the diminishing frequency with which the operation was performed between 1937 and 1942 (Table III). However, many of these operations were performed soon after the operation was introduced into this country-in fact 108 were performed during 1937 and 1938 alone. It was inevitable, in those early days, that many patients were operated on who would now be considered unsuitable. Turning to the credit side of the picture, moreover, nearly half the patients were alive, symptomless, and working eight years on the average after their operations-46 per cent in the "standard" group and 43 per cent in the "combined" group. These results were achieved in a group of patients who would have had a poor prognosis, for most had positive sputum tests and often considerable cavitation, and they could not be treated by artificial pneumothorax because of adhesions. Many also had bilateral disease.

It would obviously, therefore, be of great advantage to deduce from the available data any information about factors influencing prognosis after operation. To this end the hundred cases treated by the "standard" procedure have been divided into two large groups: (a) successful cases, in which no serious or lasting complications arose, and in which the patient returned to a normal life 
with the disease well under control ; and $(b)$ unsuccessful cases, in which the operation either led to death or left the patient worse or no better off than before. Any doubtful case has been deemed unsuccessful but nearly every case fell readily into one or other group. Not all the patients who died were necessarily unsuccessful cases-four of the remote deaths occurred after the extrapleural pneumothorax had been well stabilized for several years, and these cases have been included in the successful group. Conversely, four patients who are still alive but with marked symptoms have been included in the unsuccessful group.

By these criteria there were, in the "standard" series, fifty-five successful and forty-five unsuccessful cases.

The cases were then divided into various categories according to age and sex, length of history before operation, .radiological appearances, and extent of disease in the contralateral lung. In each category the percentage of successful and unsuccessful cases was determined. Difficulties arose in assessing the radiological features. Judgment of the degree of fibrosis from postero-anterior radiographs is open to so much error that no attempt has been made to assess the cases from this aspect. The cases were, however, divided into two categories according to whether the cavity appeared to

TABLE $X$

ANALYSIS FACTORS ASSOCIATED WITH SUCCESSFUL AND UNSUCCESSFUL RESULTS IN ONE HUNDRED PATIENTS SUBMITTED TO THE "STANDARD" OPERATION

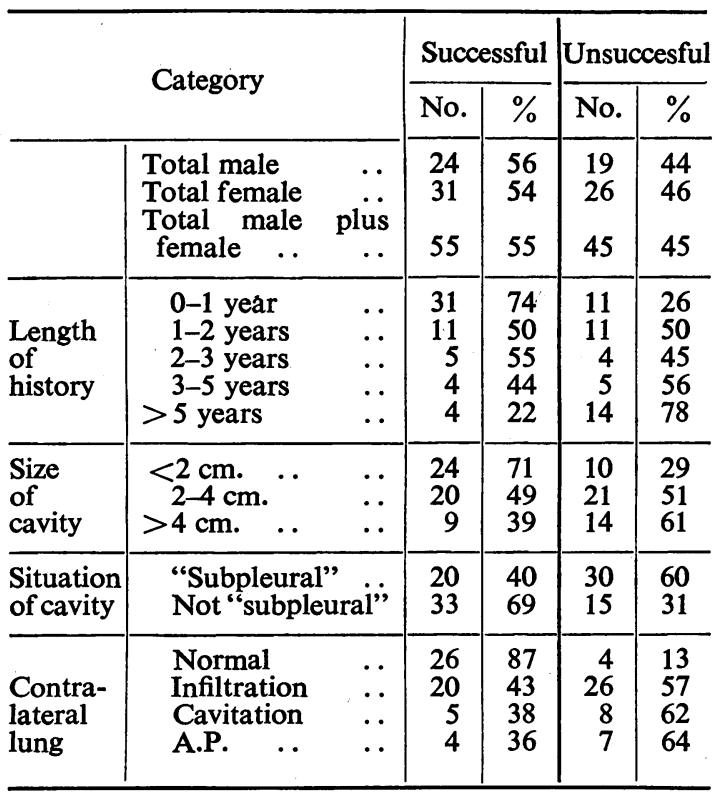

be subpleural or not, though it was realized that this criterion involves a fallacy in that a cavity may appear to be central in the postero-anterior radiograph and yet may well be subpleural either anteriorly or posteriorly.

Radiographs were not available at the time of review for two male patients in the "successful" group. The results of this analysis, which are tabulated in Table $\mathrm{X}$, were as follows.

AGE AND SEX.-The numbers in the various age groups are too small for the results to be of any significance and therefore they are not tabulated in Table X. No difference at all is apparent in the results in the two sexes.

LENGTH OF HISTORY.-The prognosis appears to vary directly with the length of history of symptoms before operation-the shorter the history the better the prognosis. In those cases with a history of less than one year, 74 per cent were successful, while in those with a history of five years or over, only 22 per cent were successful.

Size of CAVITY.-The greatest transverse diameter of the cavity or system of cavities was measured in centimetres. The figures show that the success of the operation varied inversely with the size of the cavity. With cavities of $2 \mathrm{~cm}$. or less in maximum diameter 71 per cent were successful, while with cavities of over $4 \mathrm{~cm}$. in diameter only 39 per cent were successful.

Position of Cavity.-Cases in which the cavity was subpleural as judged by the postero-anterior radiograph had a considerably worse prognosis than those in which the cavity was more central.

EXTENT of Disease in the CONTRalateral LUNG.-As would be expected, those cases with no disease in the contralateral lung at the time of operation fared better than those in whom the disease was already bilateral. Of the completely unilateral cases, 87 per cent were successful.

The criteria suggesting a good prognosis appear therefore to be (1) a short history; (2) a small cavity which is not obviously subpleural; and (3) the absence of important disease in the contralateral lung.

These criteria are in conformity with those of Monod (1938) and of Dolley, Jones, and Skillen (1940). Monod considered that "the recent and discretely developed lesion with a small cavity situated at a distance from the periphery "was the ideal type of case for the operation. He warned against the dangers of performing the operation in the presence of fibrous disease or of large cavities, especially when these are subpleural, or of longstanding lesions "with a rigid shell." Dolley, 
Jones, and Skillen divided their indications into three grades: absolute, broad, and conditional. Their "absolute" indications were: that artificial pneumothorax had failed, that cavities were neither fibrotic nor stiff-walled, were not more than $4 \mathrm{~cm}$. in diameter, and did not extend below the sixth rib posteriorly, that the contralateral lung was free of active tuberculosis, and that the lesions were non-acute, recent, and limited in extent.

\section{Review of Thirty "Good Risk" Cases}

The number of cases in which all the above criteria were obeyed was very small-only nine amongst the hundred cases submitted to the "standard" procedure. There were, however, thirty patients in the "standard" group with a history of symptoms for less than two years and whose cavities were less than $3 \mathrm{~cm}$. in maximum diameter. These thirty "good risk" cases have been assessed separately.

They consist of fifteen men and fifteen women with ages ranging from 13 to 46 years (average 28 years). In all but four an artificial pneumothorax could not be induced or had been abandoned because of contraselectivity. In only eight was the cavity deemed to be subpleural. The extent of disease in the contralateral lungs was: no disease, 15 cases ; infiltration only, 14 cases ; cavitation, 1 case. In none of these cases was there an artificial pneumothorax for treatment of disease in the contralateral lung.

Five patients are known to have died, and the remaining twenty-five have been traced for an average follow-up period of eight and a half years. There was only one postoperative death, six and a half months after operation, from pyogenic infection of the extrapleural space. There were no late deaths. Three remote deaths occurred from spread of pulmonary tuberculosis, four and a half, six and a half, and eight years respectively after operation, and one from nephritis one year after operation. Of the twenty-five living patients, thirteen had had their pneumothoraces voluntarily abandoned after an average period of 4.8 years ; all these were symptomless after an average period of 3.9 years since abandonment. Nine were alive and symptomless after early obliteration of their extrapleural spaces after an average period of 1.1 years ; the average follow-up after obliteration was a further seven years. Two patients eventually required a thoracoplasty, one because of spread of the disease four years after operation, and one because of pyogenic infection of the extrapleural space six months after operation. Both are alive and well, though the latter has a discharging sinus. One patient had an oleothorax induced shortly after operation; but after three months, during which he was progressing well, he was lost sight of and has not been traced.

Complications in the " Good Risk" Cases.There were no instances of tuberculous infection of the extrapleural space and only two of pyogenic infection, both associated with bronchopleural

TABLE XI

\begin{tabular}{|c|c|c|c|}
\hline Deaths & $\begin{array}{l}\text { Postoperative } \\
\text { Late .. } \\
\text { Remote } \quad \text {.. }\end{array}$ & $\begin{array}{l}1(3.3 \%) \\
4(\overline{13.3 \%})\end{array}$ & $16.7 \%$ \\
\hline Alive .. & $\begin{array}{l}\text { Well: } \\
\text { Continuing refills } \\
\text { Voluntarily abandon } \\
\text { Obliterated ... } \\
\text { Thoracoplasty } \\
\text { Oleothorax .. } \\
\text { With sinus after thor } \\
\text { acoplasty: }\end{array}$ & $\begin{array}{r}\overline{13} \\
9 \\
1 \\
1 \\
1\end{array}$ & $80 \%$ \\
\hline
\end{tabular}

fistula. Seven patients developed a persistent sterile effusion which led to obliteration of the extrapleural space. There were two instances of postoperative haemorrhage, but both patients recovered satisfactorily after thoracoscopy and evacuation of blood clot. The progress of the thirty patients in the "good risk" group is summarized in Table XI.

\section{Conclusions aNd Summary}

1. One hundred and twenty-eight patients who were treated by extrapleural pneumothorax at the Brompton Hospital for pulmonary tuberculosis between May, 1937, and May, 1942, have been followed up.

2. All except five patients ( 4 per cent) have been traced either to the time of death or for at least five years. Fifty-six (44 per cent) were dead ; 58 (45 per cent) were alive, symptomless, and working ; and 14 (11 per cent) were alive with symptoms. The average follow-up period of the seventy-two living patients was eight years.

3. In twenty-eight cases the extrapleural pneumothorax was joined at or shortly after operation to an intrapleural pneumothorax on the same side (the "combined" operation); in a hundred cases the extrapleural pneumothorax alone was established (the "standard" operation).

4. The postoperative mortality was 14 per cent with the "standard" operation and 21 per cent with the "combined" operation. The incidence 
of tuberculous infection in the extrapleural space was 13 per cent in the "standard" and 28 per cent in the "combined" series. The incidence of other postoperative complications was also high in both series.

5. Forty-five per cent of the patients, however, were alive, symptomless, and working, and very few late complications had arisen once the extrapleural pneumothorax had been satisfactorily stabilized.

6. In thirty-one cases the extrapleural pneumothorax had been voluntarily abandoned after an average period of five years.

In 27 (84 per cent) of these cases no relapses or complications had arisen during a further average period of three and a half years since abandonment.

7. A study of the hundred "standard" cases revealed that the main factors leading to a successful outcome for the operation were: $(a)$ a short history ; (b) a small cavity which was not obviously subpleural ; $(c)$ minimal disease in the contralateral lung. The findings are in agreement with the indications of Monod (1938) and the "absolute" indications of Dolley, Jones, and Skillen (1940).

8. There were thirty "standard" cases with a history of symptoms for less than two years and a cavity of less than $3 \mathrm{~cm}$. in maximum diameter. Twenty-four ( 80 per cent) of these patients were alive, symptomless, and working and only one died postoperatively.

I wish to thank Dr. Geoffrey Marshall, who suggested and guided this investigation; Prof. A. Bradford Hill for advice on the statistical value of the figures; and the Medical Committee of the Brompton Hospital for permission to carry out the investigation and to publish this paper.

\section{REFERENCES}

Dolley, F. S., Jones, J. C., and Skillen, J. (1940). 'Amer. Rev. Tuberc., 41, 403.

Monod, O. (1938). J. thorac. Surg., 8, 150. 